\title{
Promoting and Implementing Digital STEM Education at Secondary Schools in Africa
}

\author{
Denis Gillet*, Bosun Tijani ${ }^{\dagger}$, Senam Beheton ${ }^{\ddagger}$, Juan Carlos Farah* Diana Dikke ${ }^{\S}$, \\ Aurelle Noutahi ${ }^{\ddagger}$, Rosa Doran $₫$, Nuno R. C. Gomes ${ }^{\Uparrow}$, Sam Rich" , Ton de Jong** and Célia Gavaud ${ }^{\dagger \dagger}$ \\ ${ }^{*}$ School of Engineering, Ecole polytechnique fédérale de Lausanne (EPFL), Lausanne, Switzerland \\ Email: denis.gillet@epfl.ch and juancarlos.farah@epfl.ch \\ ${ }^{\dagger}$ CcHUB, Lagos, Nigeria and School of Management, University of Leicester, UK \\ Email: bosun@cchubnigeria.com \\ ${ }^{\ddagger}$ EtriLabs, Cotonou, Benin \\ Email: senam@etrilabs.com and aurelle@etrilabs.com \\ $\S$ Innovation Department, IMC AG, Saarbrücken, Germany \\ Email: diana.dikke@im-c.de \\ 『NUCLIO - Núcleo Interativo de Astronomia, S. Domingos de Rana, Portugal \\ Email: rosa.doran@nuclio.pt and nuno.gomes@nuclio.pt

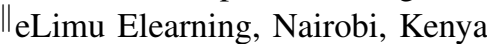 \\ Email: sam@e-limu.org \\ ** Department of Instructional Technology, University of Twente, Enschede, The Netherlands \\ Email: a.j.m.dejong@utwente.nl \\ ${ }^{\dagger \dagger}$ MITO Technology, Milano, Italy \\ Email: celia.gavaud@mitotech.eu
}

\begin{abstract}
This paper discusses an ongoing initiative aimed at promoting and implementing digital STEM education at secondary schools in Africa. This initiative, coined Go-Lab Goes Africa (GO-GA), is an innovation action supported by the European Commission through its H2020 Framework Programme for Research and Technological Development in Information and Communication Technologies (ICT). The general vision and the implementation strategy are outlined in detail, as well as the challenges faced and results achieved during its first year.

Index Terms-Inquiry Learning, Online Labs, Virtual Labs, Digital Education, STEM Education, Secondary School, Teacher Communities, Learning Platform, Educational Repository, Open Educational Resources, Sustainable Development Goals
\end{abstract}

\section{INTRODUCTION}

Achieving the global sustainable development goals (Fig. 1) as defined by the United Nations (UN) has proven to be a significant challenge. Although the goals span a wide variety of disciplines and industries, most of them are directly or indirectly related to and/or relying on education, including especially Quality Education, Gender Equality, Decent Work and Economic Growth, as well as Industry, Innovation and Infrastructure.

Focusing on the development of the digital economy through the implementation of digital education is a priority in Africa, acknowledging that the digital economy segment can be developed more easily and progressively than others (a mobile app can be developed in a garage by a single person). Furthermore, implementing digital education for Science, Technology, Engineering and Mathematics (STEM) also supports the acquisition of digital skills. Finally, economic

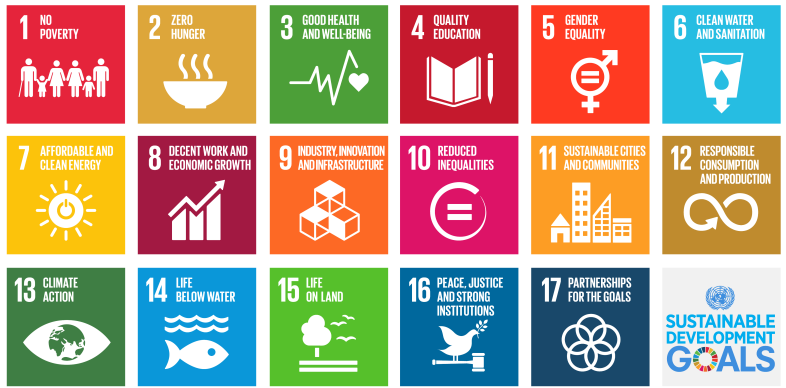

Fig. 1. Sustainable Development Goals as defined by the United Nations.

growth not only relies on core competencies in STEM, but also on transversal skills, which can effectively be developed through specific forms of digital education, such as inquiry learning and competence-based education. This is also in line with the Technology and Innovation Strategy for Africa 2024 that is part of the long-term African Union Agenda 2063, underpinned by science, technology and innovation as "multifunction tools and enablers", as well as with the 2030 Global Education Goal of UNESCO's programme Education for All [1].

It goes without question that digital education requires the availability of proper information and communication infrastructures and services. In Africa, these infrastructures and services are developed concurrently with their exploitation in digital education by following a mobile-first approach, i.e., mobile devices and $4 \mathrm{G}$ networks are supported in priority. 
Considering the general context described above and with the support of the European Commission, three African countries-namely Nigeria, Republic of Benin, and Kenyahave established a collaboration with European partners to promote and implement digital STEM Education at the secondary school level.

\section{OBjectives}

Promoting innovation and supporting effective technology transfer in developed or developing countries require unique competences, which are mainly available in research universities, high tech companies, and technology hubs. As a consequence, the project is driven in Africa by leading innovation hubs specialized in digital technology. Each innovation hub defined the needs pertinent to their respective country, and are charged with liaising with the local authorities, setting operational priorities, as well as promoting the initiative to local schools and teachers (either directly or through their communities). On the other hand, the academic and commercial partners in Europe provide support and expertise in the form of methodological and technical frameworks.

Building on the successful deployment of inquiry learning with online labs for science and engineering education at schools in Europe, while considering the local African context, the promotion and implementation strategy defined is the following:

- A core set of three countries are selected to proceed with requirements elicitation and pilot implementation. Each of these countries then extends its reach to a couple of neighboring countries.

- Support from ministries of education and local authorities is sought to get access to various schools and teacher communities (either location-based or discipline-oriented depending on the national context).

- In-service Master Teachers are selected and trained by the project partners and are then sent out as ambassadors with personalized training material to promote the inquiry learning approach and the supporting technical ecosystem in their own schools, and to develop additional educational content.

- Model digital educational resources are developed in accordance with the national STEM curricula to ease adoption.

- The science and engineering digital education ecosystem is localized in the languages of the pilot countries (especially French and Swahili) and adapted for implementation in under-connected areas and contexts (regarding both the availability of power supply and internet connectivity).

- Additional local funding and resources are gathered to support special needs and to ensure that the proper ICT infrastructures and services not covered by the European funding are made available to the Master Teachers (as a working infrastructure and a promotion tool to attract and train colleagues).

\section{Go-LAB INITIATIVE AND ECOSYSTEM}

The Go-Lab initiative launched in Europe in 2012 [2] aims at promoting science and engineering education at school. It has been and still is co-financed by a series of research and technological development projects to especially support inquiry learning with online labs [3]. Active or engaged learning - with inquiry learning as one of its implementation approaches-is proven to be effective for science education [4]-[6]. The main focus of the initiative described in this paper is on the (co-)creation of online learning spaces [7] as open educational resources integrating online labs and their exploitation in the classroom by the teachers themselves using the graasp.eu (Graasp) authoring and learning platform. These learning spaces can then be easily shared with other teachers worldwide using the golabz.eu (Golabz) sharing platform. These two loosely-coupled interoperating platforms and their content constitute the Go-Lab ecosystem [8].

To ease the adoption and the progressive implementation of a digital learning practice for science and engineering, teachers should be able to adapt their teaching scenario in an agile way. Hence, Go-Lab is promoting a blended learning approach in which the teachers just replace a few brick-andmortar laboratory sessions by the usage of online resources in a computer room, while still being present to orchestrate the activities and support their students. To support these sessions, the teachers can create online learning spaces or personalize learning spaces created by peers and published on the GoLab sharing platform. Each learning space is dedicated to study a single topic (e.g. gravity) and is implemented as a single web page accessible using a private Uniform Resource Locator (URL). Each learning space integrates simultaneously the typical inquiry learning phases through a tabular interface, featuring online labs, multimedia support resources or bookmarks, scaffolding applications (apps), as well as learning analytics. The apps are designed to support the inquiry process since the literature overwhelmingly shows that inquiry learning is only successful when the inquiry process is supported [9]. Scaffolding apps are tools that support students in their inquiry processes by giving them sufficient structure and content so that they can perform a process (e.g. hypothesis creation) that they could not successfully complete on their own [10]. Students can use the learning spaces offered by their teachers simply by providing a nickname as credentials. This simple login mechanism ensures privacy, while enabling the personal storage of learning outcomes and activity traces. These activity traces can be represented in student dashboards and can serve as input for student reflection processes.

\section{Adaptation of the Ecosystem to the African CONTEXT}

In order to adapt the Go-Lab ecosystem to the educational context of African countries, data describing the technical readiness of a sample of schools as well as prevalent pedagogical practices were collected and carefully analyzed. In March 2018, four schools were visited in Kenya (four public schools), four in Nigeria (two faith schools, one private school 
and one public school) and six in Benin (three private schools and three public schools).

The identified requirements can be summarized as follows: (1) localization of the platforms and content in terms of language and curriculum-fitness, (2) improvement of the platforms' and resources' performance whilst on poor internet connections, (3) availability of an offline-version of the Inquiry Learning Space (ILS) viewer for student use, and (4) adaptation of the platforms for mobile devices.

Regarding localization, both the Golabz and Graasp platforms have been translated into French and Swahili; the translation of resources in Swahili (e.g. inquiry apps) being still in progress. On the Golabz platform, the main interfaces, menus, and taxonomies serving as a basis for resource filtering have been translated manually by experts, whereas an automated translation mechanism has been implemented for the translation of user-generated content. This mechanism allows for the continuous update of translations as soon as new content is published or existing content is updated. Automated translation is a crucial function for a platform such as Golabz, which serves user-generated content published in various languages. User-generated content published in English is translated into French and Swahili, whereas content published in languages other than English (e.g. German) remains in the original language. This assures that teachers using the platform in French and Swahili receive the same information as teachers using the English interface.

Requirements 2, 3 and 4 are all linked to the poor internet connectivity and the prevalence of portable mobile connections identified during the field visits. Only two of the four visited schools in Kenya, three of the four visited schools in Nigeria and one of the six visited schools in Benin had wired internet connections that could be measured. For these, the global average download speed was $1.24 \mathrm{Mbps}(\sigma=1.00 \mathrm{Mbps})$, while the global average upload speed was $1.30 \mathrm{Mbps}(\sigma$ $=1.07 \mathrm{Mbps}$ ). These compare very poorly to the $2018 \mathrm{Q} 2-$ Q3 average in the United States as reported by Ookla (95.25 Mbps download, $32.88 \mathrm{Mbps}$ upload) [11]. On the other hand, mobile internet connection speed was measured in all of the schools visited. For these, the global average download speed was 6.52 Mbps ( $\sigma=4.31 \mathrm{Mbps})$, while the global average upload speed was $2.70 \mathrm{Mbps}(\sigma=0.98 \mathrm{Mbps})$. Although by a smaller margin, these values still compare poorly to the 2018 Q1-Q2 average in the United States as reported by Ookla (27.33 Mbps download, 8.63 Mbps upload) [12].

Given the low and highly variable internet speeds experienced during the school visits, the performance of the Go-Lab ecosystem had to be improved to ensure that long loading times did not render learning spaces unusable. In order to improve performance, a new Graasp application programming interface (API) was deployed to support the development of more lightweight virtual labs and inquiry apps. The new Graasp API reduces network latency by replacing previous code that performed disk input/output operations on the server every time students interacted with an app. The API also circumvents the now-deprecated OpenSocial Shindig ${ }^{1}$ server, which previously wrapped all labs and apps on Graasp before sending them to the client, and thus required additional requests to and processing on the server. Furthermore, the new Graasp API powers a new lightweight online ILS viewer that allows virtual labs and inquiry apps to communicate with each other without network requests to the server. Finally, all inquiry learning apps have been reimplemented and are now distributed via a global content delivery network (CDN), which has increased the speed at which apps render.

Although improving performance whilst on poor internet connections is an important step to facilitate the authoring of ILSs on the Graasp platform and the execution of the pilot program, schools without any fixed or mobile internet access have a high risk of remaining outside the reach of the GOGA project. In order to address this, two offline ILS viewers have been developed. A first offline viewer (shown in Fig. 2) was developed using the React Native ${ }^{2}$ JavaScript framework, which targets the iOS and Android operating systems, while a second offline viewer was developed using the Electron ${ }^{3}$ JavaScript framework, targeting the Windows, Linux and macOS operating systems. These new offline viewers follow the same user interface design as the new online web viewer, but provide some offline-specific functionalities. Firstly both viewers allow teachers to download an offline-ready version of an ILS whilst connected to the internet, which they can then share with other devices even without internet connectivity. Secondly, both viewers can come prepackaged with a specific set of ILSs. The ability to prepackage ILS inside viewers enables the creation of content-specific viewers, which could come preloaded with all the ILSs pertaining to-for instancea given subject, language, or even the curriculum of a specific country or school. Prepackaged viewers would not require any internet connection once created, and could be easily distributed for desktop operating systems using a USB key or an external hard drive.

A final requirement is to adapt the platforms for mobile devices, such as tablets and smartphones. This requirement is being addressed by three separate initiatives. Firstly, by the new lightweight online ILS viewer, which has been designed to be fully responsive and follows the progressive web app (PWA) requirements, leveraging modern web features to recreate the experience of using a native app while running on a browser. Secondly, by the development of the native offline viewer app for iOS and Android. Thirdly, by making the web versions of Graasp fully responsive. Although Golabz and Graasp are best used on desktop devices-given the nature of the authoring process - they are often visited by users on their mobile devices, as highlighted in Table I. In 2018, $18.66 \%$ of all visits to Graasp were from mobile phones, while $5.13 \%$ were from tablets, accounting for $23.79 \%$ of global visits ( $n$ $=57,034)$. Filtering only for visits from Africa $(n=3,973)$,

\footnotetext{
${ }^{1}$ https://shindig.apache.org/

${ }^{2}$ https://facebook.github.io/react-native/

${ }^{3} \mathrm{https}: / /$ electronjs.org/
} 


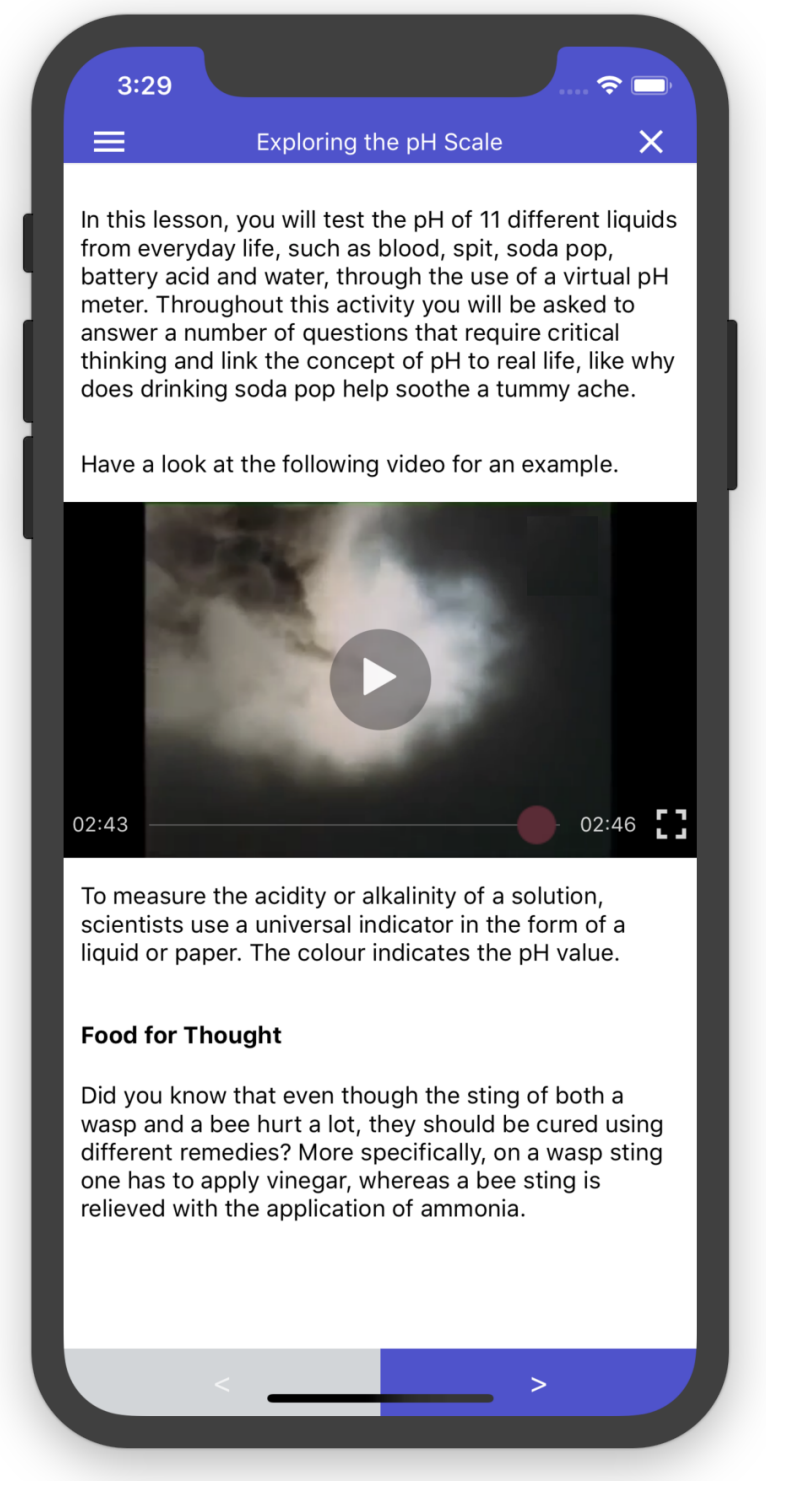

Fig. 2. The development of a mobile application allows students to access ILSs such as the one shown in this figure without an internet connection. The viewer supports text, videos, images, as well as a number of offline-ready apps and virtual labs.

however, reveals that $53.10 \%$ of visits came from mobile phones and $3.43 \%$ from tablets, accounting for $56.53 \%$ of all visits in the continent. In Golabz, $19.11 \%$ of visits were from mobile phones and $4.30 \%$ from tablets, resulting in $23.41 \%$ of all website visits globally $(n=102,917)$. On the African continent, $40.48 \%$ of visits were from mobile phones and $2.49 \%$ from tablets, corresponding to $42.97 \%$ of all website visits in Africa $(n=3,894)$. These figures clearly show that both the authoring and the sharing platforms would benefit strongly from functional mobile-friendly versions, particularly when taking into consideration usage patterns in Africa.

Adapting the Go-Lab ecosystem to tackle the four aforementioned requirements enables the successful deployment of the pilot program in Kenya, Nigeria and Benin. Moreover,
TABLE I

PERCENTAGe OF VISITS IN 2018 TO THE GRAASP AND GoLABZ PLATFORMS COMING FROM MOBILE PHONES AND TABLETS.

\begin{tabular}{|c|c|c|c|}
\hline Platform & Device Type & $\begin{array}{c}\text { \% of Visits } \\
\text { (Globally) }\end{array}$ & $\begin{array}{c}\text { \% of Visits } \\
\text { (Africa-Only) }\end{array}$ \\
\hline \multirow{2}{*}{ Graasp } & Mobile Phone & $18.66 \%$ & $53.10 \%$ \\
\cline { 2 - 4 } & Tablet & $5.13 \%$ & $3.43 \%$ \\
\hline \multirow{2}{*}{ Golabz } & Mobile Phone & $19.11 \%$ & $40.48 \%$ \\
\cline { 2 - 4 } & Tablet & $4.30 \%$ & $2.49 \%$ \\
\hline
\end{tabular}

by reducing the dependence on internet connectivity and expanding the list of supported devices, it helps lower the barriers to entry for schools looking to participate in the GOGA project.

\section{Social Relations And Structure as Adoption ENABLERS}

The analysis of the role of social structure and relations in the diffusion of technology is an essential and vibrant area of study that includes a vast set of case studies suggesting some vital regularity according to Valente and Davis [13]. In education, the complexity at the heart of successful innovation reflects a combination of mechanisms and factors that interact in open systems. The interaction between an innovation, the innovator and social setting in which the innovation occurs determines the success or otherwise the adoption and diffusion of innovation within the education sector. Despite the growing attention given to the documentation of the importance of interpersonal relationships in education, research in the field is still quite young, with an increasing number of studies appearing in journals and books [14].

Diffusion of innovation theory suggests that agency and social relations influence opinion and judgment. Understanding how innovation occurs according to Rogers [15] consists of four "key elements: innovation, which is communicated through certain channels over a period of time and amongst the members of a social system". According to Hall [16], understanding the diffusion process provides an opportunity to know how deliberate activities of companies and governmental institutions, including financing research and development, technology transfer and releasing new products, result in progress in economic and social welfare that is usually the expected outcome of the activities.

The four elements of diffusion of innovation proposed by Rogers provides an additional framework for supporting the uptake and diffusion of GO-GA within and beyond the target countries.

Innovation: According to Rogers, innovation is "an idea, practice or object that is perceived as new by an individual or another unit of adoption". Studies in science classroom practices in Africa revealed that teachers use several transmissionist and constructivist approaches in teaching. GO-GA is as such a significant progress in state-of-the-art which aims to empower a community of local teachers to build ILSs to enhance learning opportunities for students participating in STEM classes [17]. 
Communication: At the heart of the diffusion theory by Rogers is the imitation of peers within a network who have adopted an innovation. This implies the importance of communication channels as one of the determinants of the diffusion of innovation. Rogers described communication channels as "means by which messages get from one individual to another". The form of relationship between individuals with respect to information-exchange according to the theory will determine whether the transmission of an innovation will happen or not, and its effect.

By engaging existing teacher networks and governments in the three pilot countries to select and train 120 Master Teachers (trainers), communication channels have been designed to be at the core of GO-GA. Working with the Master Teachers to contextualize and localize the channels for transmitting information on the innovation, the project will support the introduction of digital laboratories-in the form of ILSs-in 120 schools, with a consortium monitoring the pilot, provisioning day-to-day support, and measuring adoption levels and assessment evaluation.

Time: According to Rogers, time is an aspect of every activity and as such does not exist independently. In diffusion of innovation, it manifests itself in three ways, described as (1) "decisions to adopt or reject", (2) "earliness or lateness of adoption" and "rate of adoption".

Social System: It is "a set of interrelated units that are engaged in joint problem solving to accomplish a common goal" [15]. Diffusion of innovation thus relies heavily on this element as it happens within the boundary of a social system, and the structure of the system influences the diffusion of innovation in many ways.

The implementing partners of this technology transfer project is a consortium of eight European and African organizations dedicated to improving participation in STEM subjects amongst secondary school students in Africa. Five of them are technical partners (European) with little influence and relationship with actors within the education sector in Africa. On the other hand, the three African partners are local community-based organizations who are in STEM education and use technology in schools in Nigeria, Benin and Kenya. These partners are responsible for the introduction and support of the use of ILSs in schools across Africa.

The consortium engages existing teacher networks while creating a new network of GO-GA teachers across participating countries. The governments are also being engaged and playing a key role in the introduction of GO-GA to schools; providing regulatory oversight and acting as non-financial sponsors where required. Ministry of Education representatives in some of the participating countries-amongst other key stakeholders - constitute the advisory board, which steers the activities of the consortium as they drive adoption of GO-GA during the pilot and beyond, as well as open up discussion on policy reform regarding the use of technology in schools.

\section{EARLY ADOPTION AND DISSEMINATION}

An important component for the implementation of the GO-GA strategy is the organization of a series of training events where a selection of teachers gets acquainted with the project ecosystem and the associated methodologies. These cohorts of teachers are the GO-GA Master Teachers, individuals capable of training and supporting other teachers in their schools/regions. During dedicated bootcamps, Master Teachers are introduced to the Go-Lab ecosystem and have the opportunity to explore the multiple resources available for the construction of their ILSs. They learn how to structure their own ILSs and how to enrich them with the existing scaffolding apps. During these events a step-by-step introduction to inquiry-based learning (IBL) is presented and teachers have the opportunity to test their own ideas. They have the opportunity to slowly migrate their already existing lessons to a more student-centered approach while learning about inquiry and interdisciplinary based learning. Master Teachers also receive tips on how to engage their peers and how to build a community in their school/region following the five pillars of community building created in the framework of the Go-Lab project. Their progression as GO-GA users/trainers follows a competence profile-also created for Go-Lab-having their competencies endorsed by a series of digital badges and certificates.

As an example of early adoption and dissemination, the case of Benin is detailed below.

\section{A. Community Building and Implementation in Benin}

GO-GA communities were established in two regions of Benin: one in the south (Cotonou and Porto Novo) with relatively better infrastructure regarding internet and power access, and one in the northern region (Parakou), considered remote, with scarce resources and limited access to the internet.

The communities are composed of STEM teachers (Life Sciences, Physics, Chemistry, and Mathematics). The requirements for membership is to own a computer, to have basic computer literacy, and to have the desire to discover and learn new ways of teaching and engaging students.

To involve teachers in the use of the ecosystem and to spread the word, activities like school visits, hackathons, and informative sessions were organized. Discussion fora were also set up to motivate teachers, share information and follow up on activities. Teachers who already joined the community were encouraged to refer GO-GA to their peers by talking about the project.

Adaptation to Curricula and Model ILSs: Since 1990, Benin has embarked on a significant reform of its curricula. Bolstered by UNESCO and the OECD, the design of these new study programs was supported by Belgian and Québécois education researchers who participated in working groups during the mid-1990s. These programs, built on the competencybased approach, were set up in 2001 at the secondary level, after being implemented at the primary level.

They were adapted for all subject levels, and curricula were reviewed accordingly. Subjects such as Physics, Chemistry, 
Biology, and Geology in the old curriculum were renamed respectively Physics, Chemistry and Technology (PCT), and Life and Earth sciences. The difficulties encountered in the implementation of the competency-based approach were the lack of library and didactic materials, as well as the lack of materials and laboratories for experimentation to accommodate a large number of students in classrooms.

Within this context, the Go-Lab ecosystem can be a valuable and powerful complementary tool for Benin STEM teachers. It not only provides online laboratories but also helps increase the interest of young students in STEM by enabling them to explore a range of scientific subjects, as well as to develop digital skills. However, the language barrier and the lack of suitable labs adapted to the Benin curriculum on Golabz, led to the localization of the available and relevant labs and the creation of new ones from scratch. Benin GO-GA community members identified topics for which it was necessary to develop laboratories with a focus on the most challenging subjects taught in schools.

To prepare the first pilot schools and offer resources for hands-on training sessions, Benin designed two model ILSs. These model ILSs combine a set of online labs in line with Benin curricula, and French language multimedia resources and apps.

Teachers identified and designed model ILSs related to Life and Earth Sciences, and PCT. The model ILSs were created with labs that illustrate abstract concepts that are hard to explain to students and recurrent in the curriculum.

Partnerships: For the successful implementation of the GOGA project in Benin it was essential to involve stakeholders in education. EtriLabs, the partner in charge of implementing the project in Benin, initiated a memorandum of understanding (MoU) with the University of Abomey-Calavi (UAC), the largest university in the country. The agreement aims to create a framework for the training of the future science teachers on the IBL concepts and practices, and to help them master the Go-Lab ecosystem. The partnership provides support for computer science students to consolidate their digital and entrepreneurial skills through the development of virtual laboratories and scaffolding apps. Finally, the partnership will allow future STEM teachers to be trained and conduct research related to active learning methodologies using the implementation in secondary schools of the GO-GA project.

To quickly build a library of laboratories adapted to Benin curricula, EtriLabs and EPFL formed a partnership for the strengthening of Benin developers computer programming skills with the aim of setting up a local pool of software engineers who will be able to create high-performance STEM laboratories.

\section{BOоTCAMPS}

Master Teacher bootcamps were separately held in the three pilot countries following a common program defined by the consortium and adapted to the educational context of each country by the respective African partners.
The selection of the STEM teachers-soon to be Master Teachers-was based on criteria independently decided by the Selection Committees of the pilot countries. The committees had to include representatives of the three African partner organizations and of key education stakeholders, such as the Ministries of Education or teacher training organizations, but no additional restrictions were imposed as to the number of members a committee should contain. The criteria were independently decided by each committee according to the educational and teaching context of the respective country. Nevertheless, teachers had to have an adequate ICT level and previous contact with the Go-Lab ecosystem through the participation in at least one of the previous training workshops organized by each of the African partner institutions in the respective countries. Upon selection for the bootcamp, the teachers underwent intensive training sessions on the GO-GA methodology for three days.

In line with the directives and goals of GO-GA, priority was given to secondary level STEM teachers in the selection for the Master Teacher bootcamps. Overall, 105 teachers from 75 public and private schools were selected for the bootcamps, above $95 \%$ of which were Bachelors or Masters of Science Education (a minority had a $\mathrm{PhD}$ or other post-graduation on a STEM area). Fig. 3 illustrates the number of selected Master Teachers and number of participating schools per pilot country, as well as the total number of ILSs produced by the Master Teachers upon the conclusion of the bootcamps. Fig. 4 indicates the ratios of number of ILSs created per Master Teacher and participating school in the bootcamps for the three pilot countries.

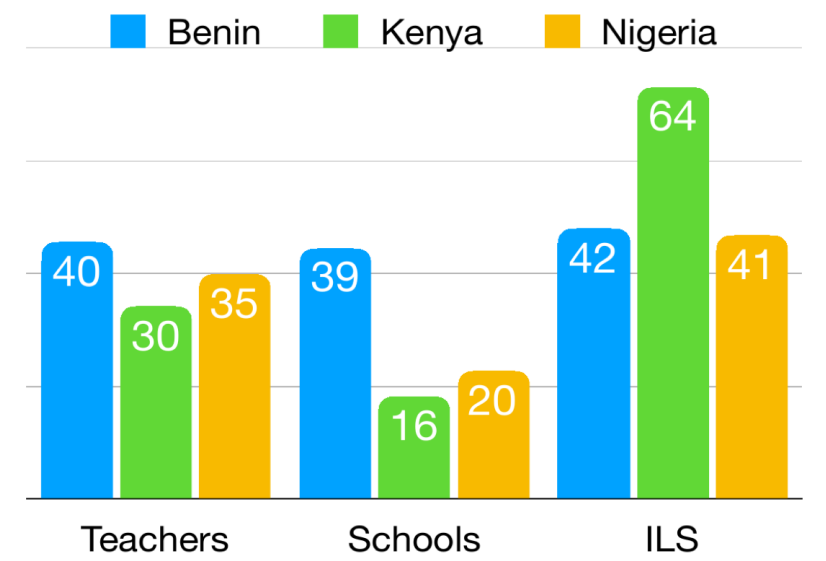

Fig. 3. Total number of Master Teachers (left), participating schools (center) and created ILSs (right) in the first series of bootcamps.

From the figures, it can be concluded that overall, the ratios of ILSs created to the total number of Master Teachers and to the total number of participating schools were respectively 1.4 and 2.0, i.e., approximately two ILSs were created per participating school, given that-on average-each teacher created more than one ILS in the bootcamps. Kenya is the country with the largest ILS-to-teachers and ILS-to-schools ratios. Although Benin is the country with the largest numbers 

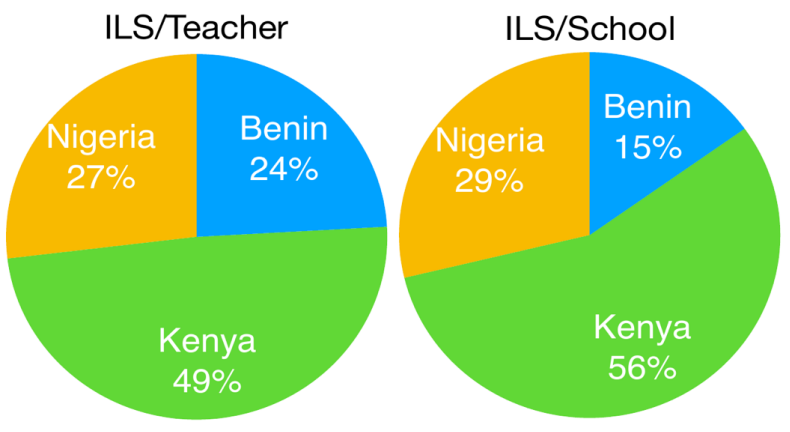

Fig. 4. Ratios of ILSs created per Master Teacher (left) and per participating school (right) for the three pilot countries. Clearly, Kenya leads the score in both regards.

of participating teachers and schools, the total number of ILSs created was similar to Nigeria's, which had about half of the number of schools participating in the training. One reason for these differences certainly has to do with the selection criteria for Master Teachers in Kenya, where teachers were put into contact to the Go-Lab ecosystem and IBL methodology in three pre-level training sessions prior to the definite bootcamp. When arriving to the final training, teachers had already prepared and used at least one ILS in their classrooms, therefore feeling comfortable in using the Graasp platform, as well as some apps and virtual labs. The results in Kenya might also indicate the importance of having at least two Master Teachers in each participating school, that can support each other in the training process and implementation of the project, while contributing, at the same time, to fostering collaborative work.

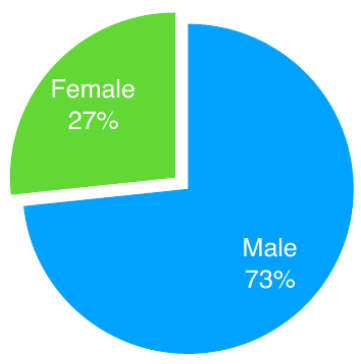

Fig. 5. Overall Master Teachers gender spread in the three pilot countries. The graph indicates a strong gender imbalance, with male teachers prevailing in a ratio of approximately 7 -to-3.

Fig. 5 illustrates the overall gender spread in the three pilot countries. The chart indicates a strong gender imbalance in the set of Master Teachers, reflecting a predominance of male STEM teachers in a ratio of about 7-to-3, which is also a fair representation of gender at system level. The imbalance is stronger in Benin and less significant in Nigeria (Fig. 6).

The distribution of STEM subjects per pilot country is represented in Fig. 7. On average, each teacher created an ILS during the bootcamp, so this graph is also indicative of the total number of ILSs produced so far for each of the STEM subjects. Physics, Chemistry and Biology are the most popular subjects among the set of selected Master Teachers.

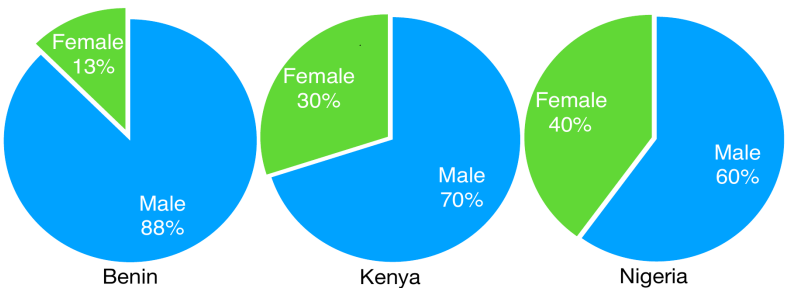

Fig. 6. Gender spread of Master Teachers in Benin (left), Kenya (center) and Nigeria (right). The male-to-female ratios are approximately equal to 9-to1, 7-to-3 and 6-to-4, respectively. The gender imbalance is more relevant in Benin than in the other two countries.

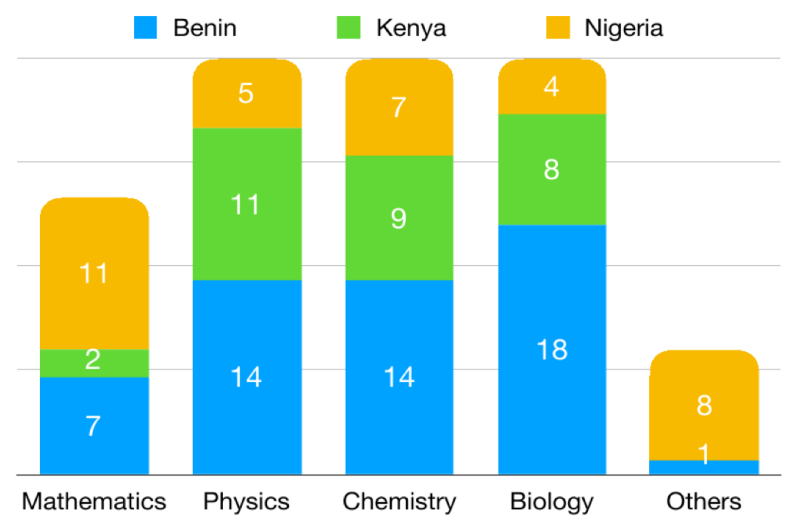

Fig. 7. Distribution of the STEM subjects taught by the selected Master Teachers in the three pilot countries. The graph is also representative of the main topics of the ILSs created during the bootcamps. Overall, Physics, Chemistry and Biology are the most represented subjects.

As mentioned in Section VI-A, in Benin, Physics and Chemistry are taught together in a single subject named PCT. Consequently, both subjects are represented by the same number of teachers, and some of the ILSs created by them combined concepts from both disciplines.

In Kenya, the number of Master Teachers lecturing Mathematics is not well represented, which had an impact on the number of ILSs produced on this subject. The team is however developing efforts in order to balance these numbers upon the delivery of the Train-the-Peers Program and the large-scale teacher onboarding during the first pilot phase.

Above $95 \%$ of the participants considered the bootcamp very useful, and demonstrated a strong will to implement the methodology in their classroom and to train other teachers in the use of the Go-Lab ecosystem.

\section{CONCLUding Remarks}

This paper describes the strategy devised to ensure an effective dissemination and a broad adoption of both inquiry learning practices and of the Go-Lab ecosystem to support science and engineering education at secondary schools in Africa. In response to lessons learned during the first year of the project, additional actions have been initiated, such as a collaboration between EPFL and local partners in Africa to build national developer communities. These communities aim to broaden the open educational resources available, especially 
virtual labs that can be used offline. Similarly, efforts to reach pre-service science and engineering teachers have been set in motion, drawing on the experience of the initial Master Teacher training sessions. Finally-in order to better support the African curricula-there are plans to incorporate additional STEM fields (including Agriculture, Health, and Computational Thinking) to the Go-Lab ecosystem. The aim is now to refine the strategy applied during the first year to maximize reach and impact. As the second year of the project starts, the lessons learned will be critical in ensuring the successful adoption of the Go-Lab ecosystem during the upcoming pilot programs.

\section{ACKNOWLEDGMENT}

The work presented in this paper is carried out in the framework of the GO-GA and Next-Lab projects co-funded by the European Union's Horizon 2020 research and innovation programme under grant agreement numbers 781012 and 731685, respectively.

The co-authors acknowledge the contributions of Sola Olateju and Nissi Madu in Nigeria, Murielle Anatohon and Zan-N'ké Beheton in Benin, Wairimu Magondu in Kenya, André Nogueira and Hassan Abdul Ghaffar in Switzerland, as well as Fer Coenders in the Netherlands.

\section{REFERENCES}

[1] United Nations Educational, Scientific and Cultural Organization, "Education for All Movement", Retrieved 11 Jan 2019, http://www.unesco.org/new/en/archives/education/themes/leadingthe-international-agenda/education-for-all/.

[2] T. de Jong, S. Sotiriou, and D. Gillet, "Innovations in STEM education: The Go-Lab federation of online labs", Smart Learning Environments, vol. 1, no. 3, pp. 1-16, 2014.

[3] T. de Jong, M. C. Linn, and Z. Zacharia, "Physical and virtual laboratories in science and engineering education", Science, vol. 340, no. 6130, pp. 305-308, 2013.

[4] C. d'Angelo, D. Rutstein, C. Harris, R. Bernard, E. Borokhovski, and G. Haertel, Simulations for STEM learning: Systematic review and metaanalysis, Menlo Park, CA: SRI International, 2014.

[5] S. Freeman, S.L. Eddy, M. McDonough, M.K. Smith, N. Okoroafor, H. Jordt, and M. Pat Wenderoth, "Active learning increases student performance in science", PNAS, vol. 111, no. 23, pp. 8410-8415, 2014.

[6] L.K. Smetana and R.L. Bell, "Computer simulations to support science instruction and learning: A critical review of the literature", International Journal of Science Education, vol. 34, pp. 1337-1370, 2012.

[7] M.J. Rodrguez-Triana, S. Govaerts, W. Halimi, A. Holzer, Ch. Salzmann, A. Vozniuk, and D. Gillet, "Rich open educational resources for personal and inquiry learning: Agile creation, sharing and reuse in educational social media platforms", International Conference on Web and Open Access to Learning (ICWOAL), Dubai, November 25, 2014.

[8] D. Gillet, M.J. Rodrguez-Triana, T. de Jong, L. Bollen, and D. Dikke, "Cloud ecosystem for supporting inquiry learning with online labs: Creation, personalization, and exploitation", 4th Experiment@ International Conference (EXP.AT), Faro, Portugal. June 2017.

[9] L. Alfieri, P.J. Brooks, N.J. Aldrich, and H.R. Tenenbaum, "Does discovery-based instruction enhance learning", Journal of Educational Psychology, vol. 103, no. 1, pp. 1-18, 2011.

[10] T. de Jong and A.W. Lazonder, "The guided discovery principle in multimedia learning", In R. E. Mayer (Ed.), The Cambridge handbook of multimedia learning, 2nd ed., Cambridge: Cambridge University Press, pp. 371-390, 2014.

[11] Ookla, "The 2018 Speedtest U.S. Fixed Broadband Performance Report", Retrieved 9 Jan 2019, http://www.speedtest.net/reports/unitedstates/.
[12] Ookla, "The 2018 Speedtest U.S. Mobile Performance Report", Retrieved 9 Jan 2019, http://www.speedtest.net/reports/unitedstates/2018/Mobile/.

[13] T.W. Valente and R.L. Davis, "Accelerating the diffusion of innovations using opinion leaders", The Annals of the American Academy of Political and Social Science, vol. 566, no. 1, pp. 55-67, 1999.

[14] K. Kirkland and D. Sutch, Overcoming the barriers to educational innovation, Bristol, UK: Futurelab, 2009.

[15] E.M. Rogers, "Diffusion of innovations", The Free Press, 4th ed., New York, 1995.

[16] B.H. Hall, "Innovation and diffusion", NBER Working Paper, no. 10212, National Bureau of Economic Research, 2004.

[17] N. Kalu-Uche, J. Alamina, and O. Ao, "Pedagogical practices in the teaching of science in secondary schools in Rivers State Nigeria". Journal of Research in Humanities and Social Science, vol. 3, no. 2, pp. 50-55, 2015. 